\title{
Alvarado López, Gilberto, 2006, El poder desde el espíritu. La visión política del pentecostalismo en el México contemporáneo, Libros de la Araucaria, Buenos Aires.
}

$\mathrm{U}$ na lectura atenta y en contrapunto entre las literaturas francesa, española y norteamericana entre la centuria de 1830 a 1930 nos depara una serie de sorpresas dignas de tomar en cuenta. La reconstrucción de lo trágico en las tales literaturas difiere de manera considerable. En las dos primeras, los personajes de ficción sucumben de manera irremediable. Pese a su acomodo económico, aunque siempre con el bendito miedo de perderlo todo, terminan, en una suerte de caída estrepitosa, pasando de ricos a mendigos (Lo prohibido, Miau, Misericordia, de Benito Pérez Galdós), o se debaten en condiciones de pobreza extrema (Papá Goriot, Las Ilusiones perdidas, de Balzac). Los menos pudientes sucumben frente al alcohol y la juerga (La Taberna, de Emile Zola). En la literatura del mundo anglosajón, la reacción frente a lo irremediable toma otras posturas. Se debaten entre algunos dolores de cabeza, se sienten mal moralmente porque toman dos vasos de alcohol por día, viajan a Inglaterra para distraerse y comparar la ética de ambos países, poseen problemas psicológicos que deben resolver, nombran a un advenedizo Freud, viajan como turistas a Italia, preocupados por este país tan primitivo (Tiernaes la noche de Scott Fitzgerald; Retrato de una dama, de Henry James) o se preocupan desmedidamente por el dinero, estableciendo casamientos y uniones, pensando en el destino de las cuantiosas fortunas (Prólogo de amor, de Taylor Caldwell, La heredera, de Henry James). No se encuentra en el horizonte el sucumbir. El trabajo, el dinero y la posición económica tanto bostoniana como neoyorquina (California es una tierra muy lejana y perteneciente a un mundo de aventuras) no les permiten ni asomarse a otra condición.

Esta actitud - la posición social, el trabajo, la apertura al mundo,- - es heredera de un protestantismo histórico (específicamente el calvinismo), que tanto en las clases pudientes como en las áreas marginales obró como sello y determinó conductas, actitudes y simbologías. Tanto Weber (1994) como Troeltsch (2005) son los pilares básicos para entender la profunda relación entre capitalismo y mundo protestante, entre racionalismo y mundo moderno.

Pero esta posición frente a la vida no se limita al territorio norteamericano. Si bien muchos movimientos de corte espiritual nacieron allí, pronto se dispersaron por el mundo. Tal es el caso del Pentecostalismo en México. Alvarado López, en el texto reseñado, con una rigurosidad y de manera sistemática, justamente ascética, digna de mención, nos hace ver, en los nueve capítulos de su libro, el nacimiento de este movimiento protestante, sus características y su adaptación al territorio mexicano. Sus orígenes en Estados Unidos se remontan al año 1830, en medio de una agitación religiosa, fermento heredado de la Reforma donde se conjugaron las simientes de muchos grupos religiosos actuales; hay un movimiento 
denominado de Santidad, donde se proclamaba un ascetismo particular en cuanto al alcohol y al tabaco, y una relación personal con la santidad, ambas ideas de origen metodista. Entre 1900 y 1906 estos grupos desembarcaron en Kansas y en la calle Azusa (La placita) en Los Ángeles. El autor sostiene que este movimiento surgió, según definiciones de Wilson, del descontento de la clase obrera norteamericana junto con inmigrantes mexicanos y otros grupos inmigrantes, un tanto cansados del conservadurismo de las clásicas corrientes del protestantismo tradicional. El urbanismo y el desarrollo industrial de esta época frenética y alocada pusieron en el tapete conflictos y necesidades de representación y refugio. Entre la indiferencia de los pastores y su ascetismo, y la rivalidad de la Iglesia Apostólica Romana, este movimiento sostenía que el derramamiento del Espíritu Santo no había cesado en el Pentecostés, en el siglo I de nuestra era, sino que continuaba y se manifestaba en el don de lenguas, la profecía, la predicación y las alabanzas que estos grupos manifestaban se producían en sus reuniones por el Poder del Espíritu Santo, doctrinas que sostienen actualmente todas las variantes del pentecostalismo. Desarrolla luego el autor las características, la expansión, la tipología, el impacto y las diferentes teorías que explican el desarrollo pentecostal por parte de investigadores antropológicos como Willemen, Lavive D’Epinay, Cartaxo Rolim, Jean Pierre Bastian y Manuela Cantón Delgado. En el capítulo dos se nos cuenta cómo estas ideas pasaron a México y al mundo. Prosigue nuestro autor repasando los nombres y las vicisitudes de los encargados de llevar este movimiento a México, según las propias fuentes pentecostales (El Consejero Fiel). Le siguen las características rituales y de organización, los distintos tipos de pentecostalismos (clásicos, neopentecostales, católicos carismáticos, independientes y autóctonos del tercer mundo), creencias (mitologías las llama) y los principales puntos de vista y actitudes hacia el mundo, tanto escatológicas como políticas, en el territorio azteca.

Tal como sustenta el título de la obra, el punto central del texto es la relación del movimiento pente- costal con la política mexicana. Según nuestro autor los avatares propios de México, en el terreno político institucional, acompañaron a estos movimientos en sus definiciones y elecciones. Tomando como parámetro la posición de la Iglesia Católica y sus propias definiciones y, como en el caso de Maximiliano o del Porfiriato, donde la institución católica prestó apoyo incondicional, o el rechazo a la Revolución Mexicana por parte de la misma, los pentecostales se manifestaron en sus preferencias políticas adeptos al nacionalismo de la tierra azteca. Si bien consideran que los aztecas eran idólatras y la Iglesia Católica otro tanto, se manifestaron y se manifiestan partidarios de aquellos grupos políticos que no poseen vinculación profunda con la catolicidad mexicana, como es el caso del PRI, y rechazan por tal motivo al PAN. Dos cosas van paralelas durante el siglo XX: el desarrollo y crecimiento del propio movimiento, su consolidación y el proceso de democratización de la propia política mexicana, que eclosiona en la década de los sesenta. Estos dos puntos convergen en la actualidad. Libremente, los pentecostales manifiestan sus preferencias políticas, pero esto surge, comenta el autor, por el desarrollo de la democracia en México. Se debe ver esta actitud, dice el autor basándose en Pritchard, como una respuesta a la totalidad del sistema político, a la estructura misma donde se insertan. Esto lo demuestra Alvarado López mediante un trabajo de campo en que se enseña el resultado de un trabajo de encuestas muy pormenorizado (estadística descriptiva), donde los pentecostales tomaron posición en las elecciones mexicanas de 1988, 1994 y 2000 (ver anexo de la obra). Surge la pregunta de por qué es tan marcada en México la necesidad de una pronunciación política. En otros países, como Argentina, el desarrollo democrático, consolidado desde 1983, no hizo surgir la necesidad de que movimientos protestantes tomaran posiciones políticas, que sí las tienen, pero no en la medida de incipientes actuaciones políticas que van más allá de la simple pronunciación, como en el caso de México. Aunque en Argentina la política, caterva de amores 
impuros, hace pensar en por qué no existe la necesidad de reemplazar siendo siempre los mismos fetiches y caras de sonrisas afeitadas, que tienen la osadía de no cambiar ni el maquillaje. iSerá que la necesidad de encontrar un espacio simbólico propio provoca que tomen participación política aquellos no destinados de manera original a hacerlo? ¿O la propia historia de México, con la pérdida de identidad de políticos y eclesiásticos, haga que surjan nuevos protagonistas que compitan por la captación del universo simbólico?

Para Alvarado López esto se debe al debilitamiento de la propia política mexicana y de la izquierda tradicional y el miedo, por parte del movimiento pentecostal, de que la Iglesia monopolice el poder de convocatoria, especialmente desde 1992, cuando se concibió constitucionalmente la apertura al espacio religioso. Pesan aquí también las sucesivas visitas del Papa Juan Pablo II y la nueva relación entre el Vaticano y los estamentos políticos de México. Justamente una de las creaciones más fuertes de este movimiento es el MIEPI (Movimiento Iglesia Evangélica Pentecostés Independiente), creado en 1930, y el ITE (Instituto Teológico Esdras), donde se forman los cuadros de líderes de cada Iglesia en particular.

En cuanto a sus definiciones sobre las posiciones escatológicas y su relación con la Iglesia Católica, es necesario concentrarse en determinados puntos. Las posiciones milenaristas de los pentecostales, es decir, la lectura y la interpretación del Libro de Apocalipsis, de Daniel y otros libros, como predicciones y profecías que se relacionan con movimientos políticos actuales, la sucesión de imperios, Babilonia, Grecia, Roma, y demás, no sólo son manifestadas por los pentecostales, sino por varios grupos, entre ellos los evangélicos. La lectura no exegética de dichas fuentes es compartida por la mayor parte de los grupos protestantes. De la misma manera ocurre con la definición de la Iglesia Católica como "Babilonia la Grande" o "la Ramera", la religión falsa que se prostituye con los sistemas políticos. Esta interpretación es sostenida con mucho énfasis por los Testigos de Jehová (Calzato) aunque a éstos no podemos considerarlos como un ejemplo clásico del protestantismo histórico. Pero de todas maneras también es un locus común entre los hijos de la Reforma (Woodrow). Este punto puede ser utilizado para conocer cómo cada movimiento piensa e interpreta su propia posición política frente al mundo. Los Testigos de Jehová manifiestan, por ejemplo, un exacerbado nacionalismo norteamericano, pidiendo el respeto a los patriarcas fundadores de la Nación y a su Constitución. Pero al mismo tiempo no dejan de colocar a su país (Estados Unidos) como uno de los imperios decadentes, junto con Inglaterra, naciones relacionadas con Babilonia la Grande, que verán la destrucción por parte de Dios en la batalla final en Armagedón. Siendo el pentecostalismo más plástico en sus definiciones, estructuras, y con una adaptación también plástica en cada país, puede verse en cada caso cómo definen, por ejemplo, a Estados Unidos en sus interpretaciones. Contrapunto necesario para conocer el desarrollo y las variantes. En el caso mexicano, los pentecostales han sabido interpretar la historia mexicana con base en sus propias concepciones escatológicas particulares. Nos cuenta Alvarado López que realizan un paralelo entre el movimiento de Independencia de México y la salida de Egipto de Israel, llevada a cabo por Moisés. Así como Israel se libró de sus opresores egipcios, México lo hizo de la tutela de la Iglesia Católica. Benito Juárez, para los pentecostales, es uno de los políticos más respetados por su confrontación con la Iglesia. Esto no lo han hecho los Testigos; ignoran los partidismos políticos de los países donde se encuentran, respondiendo sólo a las directivas éticas, morales, intelectuales e interpretativas de la Watch Tower con residencia en Nueva York. Estos juegos de interpretación son los que nos permiten conocer fondo y forma de cada uno de estos movimientos, sus idas y venidas, lo que nos dicen y, quizás lo más importante, lo que no nos dicen.

El texto en cuestión goza de méritos bien claros. Ya en su prólogo, Elio Masferrer Kan lo define "como un esfuerzo sustantivo" de investigación, cosa en que nos 
manifestamos de acuerdo. La bibliografía citada es concisa y muy equilibrada. Resultan claros los objetivos de investigación y las hipótesis de trabajo. Su rigurosidad es su mérito, pero también su falta. Nos gustaría haber encontrado en el texto las propias reflexiones del autor acerca de su trabajo, sus puntos de vistas, su trayectoria religiosa, el por qué del objeto de estudio, los "imponderables de la vida real", propios de toda investigación de campo, su llegada al mismo, los informantes y sus pathos así como sus reacciones frente al investigador. Elementos que complementan y dan marco a una investigación. Las lanchas que nos dejan en la orilla y las vemos irse, quedándonos solos, de una u otra manera definen el accionar del antropólogo, del sociólogo o del etnohistoriador. Esta sal que todo texto necesita es lo que reclamamos a esta investigación.

Cuando se trata de textos sobre religión, creemos, no debemos evitar poner en claro esas pequeñas puertas que nos abren paso, o simplemente los soles que nos acompañan en nuestra trayectoria. Cuando llevamos en nuestras manos tantas necesidades no podemos obviar el peso de las mismas. En cuestiones de religión, a veces tan difícil es de definir, con sus múltiples variantes, con el silencio, en algunos casos, de nuestros informantes, con el nuestro, con las miradas del otro pegadas en nuestra retina, no debemos sustraernos de poner en la mesa pecados y corazones. Whitehead decía que en el fondo toda manifestación religiosa es un asunto de soledad personal, frente a un inconmensurable universo y un caos que nos sorprende al borde de nuestros talones. Somos nosotros o el abismo. A ver quién gana. No podemos darle tregua. Ni un segundo.
Voltaire, según buenas fuentes, reía a mandíbula batiente cuando se encontró con el relato evangélico de la maldición sobre la higuera por parte de Cristo. Los textos religiosos pueden generar rechazos, risas, concesiones ineludibles. Ser víctimas o perseguidores. Quizás nadie sea el mismo luego del relato de la conversión de San Agustín en sus Confesiones. O sí o no. Por eso celebramos el texto objeto de nuestro análisis, pero esperamos que un día nos dé la sorpresa: unos granos de sal, crujientes. Un embarcarse en otras latitudes. Sabemos que la objetividad pidió el divorcio, se la dimos y aquí estamos solos y desnudos, náufragos, con una posmodernidad que, como un muñeco quebrado en su cintura, boca abajo, desfallece de manera irremediable. Malinowsky, San Pablo, Conrad y Melville sólo tuvieron y tienen un fondo en común: el mar que se atrevieron a cruzar. Este último autor decía que embarcarse en el mar sustituye la pistola y la bala. Los pentecostales, tal como nos enseña Gilberto Alvarado López, surgieron por un enorme descontento ante las instituciones que los representaban. Se atrevieron a involucrar al Espíritu Santo en su vida cotidiana. Nada menos. Alguien que venga a remediar y a comerse los monstruos que supimos conseguir.

Porque la religión, en el fondo, quizás sea eso, una clara sustitución de nuestros propios avatares. Humana, demasiado humana.

Walter Alberto Calzato Universidad de Buenos Aires Ciencias Antropológicas Escuela Nacional de Antropología e Historia 